about possible postoperative pain doctors believed that this was most often done by anaesthetists and other doctors, and nurses believed that they themselves were the main informants, but the patients said that they had been informed most commonly by their family and friends. An information sheet about postoperative pain was thought useful by $89 \%$ of patients, $75 \%$ of nurses, and $42 \%$ of doctors. Other patients felt that such information coul increase anxiety by causing them to dwell too much on the painful aspects of the operation. Egbert et al reduced analgesic requirements by half when anaesthetists spent time before the operation explaining about pain and how to reduce its severity by protecting and relaxing abdominal musculature. Other studies have also shown that oral and written information, if presented sensitively, can reduce postoperative pain and anxiety. ${ }^{67}$

The extent to which a patient's response to the first dose(s) of analgesia is assessed depends on staff being aware that requirements vary (most of the staff we questioned seemed to know this) and having the time and the inclination to carry out such an assessment. Judging by the number of visual analogue scales left uncompleted in our study, the time was often not available on account of other nursing duties. Perhaps staff:patient ratios on surgical wards should be increased to take account of this. Another possible solution is demand analgesia with syringe pumps,${ }^{8}$ but these are expensive to install and require experienced staff to educate and supervise patients in their use.

It is well known that medical and nursing staff overestimate the risk of addiction from opioid analgesia, ${ }^{149}$ and one fifth of all nurses we questioned were concerned about this. The real risk has been estimated at $1: 3000$ patients. ${ }^{10}$

The results of this study highlight deficiencies that prevent optimal postoperative pain relief. Not only are patients' expectations of pain relief low but for many the reality is even worse. These expectations need to be raised by better communication: information given to patients preoperatively not only helps but would be well received. The level of pain relief that medical and nursing staff aim to provide must also rise. Education for nursing staff in optimal administration of analgesia must reach both trainees and qualified staff to achieve and maintain a high standard.

We thank the patients and the nursing and medical staff on the surgical wards at City General Hospital for their cooperation.

1 Cohen FL. Post surgical pain relief: patients' status and nurses' medication choice. Pain 1980:9:265-74.

Cronin M, Redfern PA, Utting JE. Psychometry and postoperative complaints in surgical patients. Br $\mathcal{A}$ Anaesth 1973;45:879.

3 Cartwright PD. Pain control after surgery: a survey of current practice. Ann R Coll Surg Engl 1985;67:13-6.

4 Huskisson EC. Measurement of pain.Lancet 1974;ii:1127-31.

5 Egbert LD, Battit GE, Welch CE, et al. Reduction of postoperative pain by encouragement and instruction of patients. N Engl F Med 1964;270:825-6.

6 Leigh JM, Walker J, Janaganathan P. Effect of preoperative anaesthetic visi on anxiety. Br Med J 1977;ii:987-9.

7 Hayward J. Information-a prescription against pain. London: Royal College of Nursing, 1975. (Research project 120 .)

8 Keeri-Szanto M, Heaman S. Postoperative demand analgesia. Surg (jynecol Obstet 1972;134:647-51.

9 Marks RM, Sachar EJ. Under treatment of medical in-patients with narcotic analgesia. Ann Intern Med 1973;78:173-81.

10 Porter J, Jick H. Addiction rate in patients treated with narcotics. N Engl F Med 1980;302:123.

(Accepted 17 April 1990)

\begin{abstract}
Department of Obstetrics and Gynaecology, University of Birmingham, and Dudley Road Hospital, Birmingham

D M Luesley, MD, senior

lecturer

J Cullimore, MRCOG, research fellow

C W E Redman, MD, lecturer F G Lawton, MD, lecturer D R Williams, FIMLs, chief medical laboratory scientific officer

E J Buxton, MRCOG, research fellow

\section{Birmingham and Midland Hospital for Women, Birmingham B11 4HI T P Rollason, FRCPATH, senior lecturer \\ J M Emens, MD, consultant gynaecologist}

Correspondence to: Dr D M Luesley, Academic Department of Obstetrics and Gynaecology, Dudley Road Hospital, Birmingham B18 7QH.
\end{abstract}

\title{
Loop diathermy excision of the cervical transformation zone in patients with abnormal cervical smears
}

\author{
D M Luesley, J Cullimore, C W E Redman, F G Lawton, J M Emens, T P Rollason, D R Williams, \\ E J Buxton
}

Abstract
Objective-To determine the efficacy and morbidity of fine loop diathermy excision of the cervical transformation zone as applied to the management of outpatients with abnormal cervical smears.

Design-Prospective programme trial with six month follow up.

Setting - Two hospital based colposcopy clinics.

Patients-616 Patients aged 16-60 with abnormal cervical smears.

Interventions-After colposcopic and cytological assessment excision of the cervical transformation zone by fine loop diathermy under local anaesthesia in the outpatient department.

Main outcome measures-Time to complete the treatment, immediate morbidity in terms of discomfort and bleeding, and cytological and colposcopic findings at six months.

Results - Treatment was completed in a mean of 3.47 minutes (SD 1.99). Immediate morbidity was minimal, and histological specimens were adequate in over $90 \%$ of cases. Almost two thirds of patients were treated at their first visit to the clinic. 58 Patients $(9.4 \%)$ failed to attend for follow up at six months and one had had a hysterectomy. Of the 557 patients who attended for colposcopic and cytological follow up at six months, $506(91 \%)$ were normal cytologically and $19(3.4 \%)$ had histologically confirmed persistence of cervical intraepithelial neoplasia. The overall confirmed failure rate of the technique was $4 \cdot 4 \%$.

Conclusion-Loop diathermy excision is an effective treatment with low morbidity and is an appropriate modality for patients with abnormal cervical smears.

\section{Introduction}

The concept of excising the abnormal transformation zone of the cervix should cytological or colposcopic criteria suggest the presence of intraepithelial neoplasia is not new. Cold knife and diathermy conisation and more recently carbon dioxide laser conisation are proved effective techniques, although they require either general anaesthesia or expensive equipment. Morbidity is well documented. Outpatient excision of the transformation zone using the carbon dioxide laser has also been shown to be feasible but also requires equipment, skill, and time that are not always available.

Diathermy generators are cheap, easy to maintain, and available in nearly every hospital. With minimal adaption they can be used in an outpatient setting either to totally excise ${ }^{1}$ or take a biopsy sample of the cervical transformation zone. ${ }^{2}$ Furthermore, being an excisional method of management, treatment can be undertaken at first contact, so dispensing with the necessity for a pretreatment assessment.

There have been no large series prospectively docu- 
menting the morbidity and outcome of outpatient diathermy excision. We therefore report a programme trial of this technique carried out over 12 months.

\section{Patients and methods}

All patients who were referred to our colposcopy clinics from 1 March 1988 were included if their cytological and colposcopic characteristics rendered them suitable for local destructive treatment as an outpatient. This report documents the first 12 months' experience with patients who were eligible to complete six months' follow up. A total of 616 patients aged 16 60 (median 27) met these criteria and had been treated since the programme began. Table I gives their age distribution.

\section{PLAN OF PROGRAMME TRIAL}

Patients were selected for treatment regardless of whether it was their first or a subsequent visit to the clinic. At the time of treatment details regarding the site, size, and character of the colposcopic lesion were documented, the cervical smear was repeated, and the result subsequently added to the treatment record. The time to complete the treatment was recorded (after local analgesia), as was the depth of central destruction. Discomfort during treatment was recorded on a verbal analogue scale of none to severe. Haemorrhage was assessed as none, mild (bleeding noted but did not interfere with or extend the duration of treatment), moderate (bleeding required extended treatment time to control), or severe (treatment curtailed and surgical measures required to control bleeding). The histological outcome and adequacy of the specimen were recorded, as were any previous directed biopsies in patients who had previously been assessed.

Patients were reviewed six months after treatment. Any interim morbidity was recorded. Colposcopy was performed and a cervical smear taken. Details including duration of vaginal discharge after treatment, secondary haemorrhage, and menstrual dysfunction were recorded. The situation of the new squamocolumnar junction and its characteristics were recorded. The cytological outcome was documented as well as cytological adequacy in terms of endocervical or metaplastic cell content, or both. ${ }^{3}$ Any residual disease suspected on colposcopy or cytologically was recorded as a potential treatment failure. All potential treatment failures were reviewed three months later and if colposcopic or cytological abnormalities persisted a further biopsy sample was taken. If this contained cervical intraepithelial neoplasia a confirmed treatment failure was recorded.

If loop excision had confirmed stage $\mathrm{Ia}_{1}$, stage $\mathrm{Ia}_{2}$, or glandular intraepithelial neoplasia a formal cold knife conisation was performed.

\section{TECHNIQUE}

After completion of a colposcopic assessment local infiltration of the cervix (outside the transformation

TABLE I - Age distribution of study population of women

\begin{tabular}{lccccccccc}
\hline & \multicolumn{1}{c}{ Age (years) } & \multirow{2}{*}{ Total } \\
\cline { 2 - 8 } & $\leqslant 20$ & $21-25$ & $26-30$ & $31-35$ & $36-40$ & $41-45$ & $46-50$ & $>50$ & No(\%) of patients \\
\hline No(12) & $184(30)$ & $175(28)$ & $88(14)$ & $48(4)$ & $22(4)$ & $19(3)$ & $8(1)$ & $616(100)$ \\
\hline
\end{tabular}

TABLE II - Visit to clinic (that is, first, second, third, etc) at which loop diathermy excision was carried out

\begin{tabular}{cccccccc}
\hline & \multicolumn{8}{c}{ Visit to clinic } & \\
\cline { 2 - 7 } & 1st & 2nd & 3rd & 4th & 5th & 6th & Total \\
\hline No (\%) of patients & $400(65)$ & $167(27)$ & $31(5)$ & $13(2)$ & $4(0 \cdot 6)$ & $1(0 \cdot 2)$ & $616(100)$ \\
\hline
\end{tabular}

zone) with up to $6 \mathrm{ml}$ prilocaine (3\%) and felypressin $(30 \mathrm{IU} / 1)$ was performed. A Valleylab force 2 surgical generator and various fine wire loops were used throughout. The generator was set in a blend (cut/ coagulation) mode with outputs varying between 30 and $50 \mathrm{~W}$. The objective was to excise the whole transformation zone with one sweep of the wire loop, although in certain instances (owing to the size of the zone) this was accomplished only after several sweeps. In some instances, although the whole transformation zone was fully visualised, the squamocolumnar junction was sited within the endocervical canal and deep excisions were performed. After excision of the specimen ball diathermy fulguration of the exposed stroma was performed to achieve haemostasis if necessary. The objective was to leave a cylindrical defect with the endocervical canal central. Depth was measured to the central point of the endocervical canal.

\section{FOLLOW UP}

A total of 557 of the 616 patients attended for follow up at six months. Fifty eight defaulted and one had had a hysterectomy for an unrelated condition four months after treatment. Though tissue from that patient was available for histological review she was excluded from colposcopic follow up. Ten patients had cone biopsies performed as a result of early invasion or adenocarcinoma in situ being found in the loop excision specimen; all were followed up cytologically and colposcopically.

\section{Results}

\section{TREATMENT AND IMMEDIATE MORBIDITY}

Time of treatment and cytological picture at presentation - Table II shows at which visit to the clinic loop diathermy excision was carried out. Four hundred patients $(65 \%)$ were treated at their first attendance. Patients treated at subsequent visits had either had a previous directed biopsy confirming cervical intraepithelial neoplasia (CIN) with or without koilocytosis (CIN grade III, 66 cases; CIN grade II, 47 cases; CIN grade I, 58 cases) or had persistently abnormal smears with a fully visualised transformation zone and no histological evidence of neoplasia (45 cases). All of these patients had at least two years of a borderline or mildly dyskaryotic cytological picture before being offered loop excision. Table III gives the cytological findings at the time of treatment. Though in some patients the findings were negative at the time of treatment, all patients had had an abnormal cytological picture before referral.

TABLE III-Cervical cytological findings at time of treatment

\begin{tabular}{lc}
\hline Cytological findings & No (\%) of patients \\
\hline Borderline nuclear abnormalities & $55(9)$ \\
Atypical with koilocytosis & $22(4)$ \\
Cervical intraepithelial neoplasia: & $115(19)$ \\
Grade IIIa & $100(16)$ \\
Grade IIIa with koilocytosis & $68(11)$ \\
Grade III & $9(1 \cdot 5)$ \\
Grade III with koilocytosis & $68(11)$ \\
Grade IIIb & $25(4)$ \\
Grade IIIb with koilocytosis & $94(15)$ \\
Grade IV & $55(9)$ \\
Negative & $5(1)$ \\
Unsatisfactory & $616(100)$ \\
\hline Total &
\end{tabular}

Time to complete the treatment-Treatment was completed in a mean of 3.47 minutes (SD 1.99). Two hundred and thirty one treatments $(38 \%)$ were completed in two minutes or less, $306(50 \%)$ in three to five minutes, $77(13 \%)$ in six to 10 minutes, and only two treatments took over 10 minutes.

Depth of cervical tissue removed-The depth of destruction was less than $8 \mathrm{~mm}$ in 46 cases $(7 \%)$, 
$8-10 \mathrm{~mm}$ in 405 cases $(66 \%), 11-13 \mathrm{~mm}$ in 101 cases $(16 \%)$, and over $14 \mathrm{~mm}$ in 64 cases $(10 \%)$. These measurements are probable underestimates as the heat effect of fulguration inevitably causes some tissue shrinkage and additional thermal necrosis.

Haemorrhage and discomfort-No bleeding was recorded in 363 cases (59\%). Mild bleeding occurred in $199(32 \%)$, patients, moderate bleeding in $51(8 \%)$, and severe bleeding in three $(0.5 \%)$. In the severe cases sutures had to be used, although treatment was eventually completed as an outpatient. No discomfort was recorded by 521 patients $(85 \%)$. Of the others, 80 $(13 \%)$ recorded mild discomfort, $14(2 \cdot 3 \%)$ moderate discomfort, and only one severe discomfort. This last patient was subsequently treated under a general anaesthetic.

Adequacy of histological specimens, and findingsHistological specimens were recorded as good if no reference was made to heat artefact, average if heat artefact was mentioned but was not enough to interfere with interpretation, and poor if heat artefact has seriously compromised interpretation. Specimens were considered to be good in 529 instances $(86 \%)$, average in $68(11 \%)$, and poor in $19(3 \%)$. The average number of tissue blocks obtained per loop specimen was seven, although the range included some specimens with up to 22 blocks, particularly in those cases of adenocarcinoma in situ and early invasive disease. Table IV lists the various histological findings.

\section{TREATMENT OUTCOME AND FOLLOW UP}

Secondary haemorrhage-Of the 557 patients who attended for follow up at six months, $24(4 \cdot 3 \%)$ had excessive bleeding noted within three weeks of treatment. Three cases required suturing and the remainder responded to bed rest and antibiotics. No patient required a transfusion. Fourteen of the 24 patients had excisions greater than $14 \mathrm{~mm}$ deep.

Duration of vaginal discharge after treatment-Nearly all patients experienced some form of vaginal discharge after treatment. In 398 cases (71\%) this lasted for two weeks or less. In 31 cases $(5 \cdot 6 \%)$ the discharge was considered to be prolonged, lasting for six weeks or more. The average was $2 \cdot 17$ weeks (SD 1.52).

Cervical stenosis - In seven patients $(1 \cdot 3 \%)$ severe

TABLE IV - Histological findings in tissue obtained by loop excision

\begin{tabular}{lc}
\hline Histological findings & No $(\%)$ of patients \\
\hline Normal & $31(5)$ \\
Atypical with koilocytosis & $137(22)$ \\
Cervical intraepithelial neoplasia: & $109(18)$ \\
Grade I with or without koilocytosis & $84(14)$ \\
Grade II with or without koilocytosis & $242(39)$ \\
Grade III with or without koilocytosis & $3(0 \cdot 5)$ \\
Stage Ia & $1(0 \cdot 2)$ \\
Stage Ia & $6(1)$ \\
Adenocarcinoma in situ & $3(0 \cdot 5)$ \\
Cervical intraepithelial neoplasia & $616(100)$ \\
unspecified &
\end{tabular}

TABLE $\mathrm{v}-$ Histological and cytological findings at six month follow up and confirmed failure rate at nine months

\begin{tabular}{|c|c|c|c|}
\hline \multirow[b]{2}{*}{ Original histological findings } & \multicolumn{2}{|c|}{ Cytological findings at follow up } & \multirow{2}{*}{$\begin{array}{l}\text { No (\%) of patients confirmed } \\
\text { as treatment failures }\end{array}$} \\
\hline & Normal & Abnormal & \\
\hline Normal & 22 & 1 & 0 \\
\hline Atypical with or without koilocytosis & 112 & 9 & $1(0 \cdot 8)$ \\
\hline \multicolumn{4}{|l|}{ Cervical intraepithelial neoplasia: } \\
\hline Grade I with or without koilocytosis & 84 & 13 & $4(4 \cdot 1)$ \\
\hline Grade II with or without koilocytosis & 71 & 7 & $4(5 \cdot 1)$ \\
\hline Grade III with or without koilocytosis & 208 & 20 & $9(4 \cdot 3)$ \\
\hline 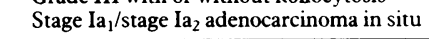 & 9 & 1 & $1(10 \cdot 0)$ \\
\hline All cases & 506 & 51 & $19(3 \cdot 4)$ \\
\hline $\begin{array}{l}\text { All cases of cervical intraepithelial neoplasia/ } \\
\text { adenocarcinoma in situ and invasion }\end{array}$ & 372 & 41 & $18(4 \cdot 4)$ \\
\hline
\end{tabular}

cervical stenosis was recorded at the six month follow up. This was defined as the inability to pass a $3 \mathrm{~mm}$ probe into the endocervical canal. In all but two patients the depth of excision had exceeded $14 \mathrm{~mm}$.

Cytological outcome and adequacy - Endocervical and metaplastic cells were noted in $302(54 \%)$ of the follow up smears. Neither of these indicator cells was recorded in $127(23 \%)$ follow up specimens. Overall $377(68 \%)$ smears contained endocervical cells and $355(64 \%)$ contained metaplastic cells. Fifty one smears $(9 \cdot 2 \%)$ were reported as abnormal. Nineteen were reported as showing borderline nuclear abnormalities with or without koilocytosis, 28 as showing mild dyskaryosis with or without koilocytosis, and three as showing moderate dyskartyosis with koilocytosis. All unsatisfactory smears $(10)$ were repeated satisfactorily before analysis. One positive smear was noted at follow up. Table $\mathrm{V}$ shows the cytological outcome at the six month follow up.

Colposcopic outcome and adequacy-The new squamocolumnar junction was visualised in 504 instances $(90.5 \%)$. The transformation zone looked normal in 462 cases (83\%); extensive metaplasia was recorded in 33 cases $(6 \%)$, residual cervical intraepithelial neoplasia was suspected in $24(4 \cdot 3 \%)$, and colposcopic evidence of human papillomavirus infection was obtained in $38(6 \cdot 8 \%)$.

Further histological specimens were obtained in 84 cases. Twenty three were taken because of residual cervical intraepithelial neoplasia suspected on colposcopy, one was a hysterectomy specimen in a patient with menorrhagia, 10 were cone biopsy samples, and the remainder were from further loop excisions performed because of persisting cytological abnormalities in the absence of other factors. Examination showed koilocytosis only in 38 cases, cervical intraepithelial neoplasia grade I with or without koilocytosis in 12 cases, cervical intraepithelial neoplasia grade II with koilocytosis in three cases, and cervical intraepithelial neoplasia grade III with koilocytosis in four cases. The remaining specimens contained no evidence of dysplasia or koilocytosis. Eighteen of 413 patients who had previously confirmed intraepithelial neoplasia, early invasion, or adenocarcinoma in situ were therefore defined as confirmed treatment failures $(4 \cdot 4 \%)$, although one case diagnosed as wart atypia only at the original loop excision was subsequently diagnosed as cervical intraepithelial neoplasia grade I at a further excision.

Overall success rate based on histological findingsTable $\mathrm{V}$ shows the potential failure rate as defined by abnormal cytological results alone at six months and the confirmed failure rate as defined by further histological studies in relation to the original histological findings after loop excision.

\section{Discussion}

Diathermy excision of the cervical transformation zone has been used for years to cut cone biopsy samples, although usually under general anaesthesia and with high voltage, non-blending generators that tended to produce quite severe thermal artefact. Prendiville et al found that by using a fine wire loop diathermy could be used to provide good biopsy material from the transformation zone in an unanaesthetised patient, ${ }^{2}$ and extension of this technique enables the whole transformation zone to be removed. Thus this procedure might be a suitable alternative to carbon dioxide laser vaporisation.

Since the mid-1970s, and more so since the introduction of call and recall for cervical cytology, there has been a great increase in the number of women requiring diagnosis and treatment as a result of having had abnormal cervical smears. The logistic implications 
of this phenomenon are plainly evident, hence the potential advantages of a cheap, effective, rapid, and safe treatment technique. Loop diathermy excision performed as an outpatient procedure seems to fulfil all these criteria with the additional advantage that it is excisional rather than ablative. Apart from providing a greater amount of material for more adequate histopathological assessment this approach allows patients to be treated at their first attendance to a colposcopy clinic. By contrast, a prerequisite of ablative treatment is histological assessment to exclude invasive disease, which necessitates an additional pretreatment visit. By removing the need for such a visit clinical resources can be maximised and patients managed effectively more quickly. From the patients' point of view this results in a negative smear sooner.

Arguably, managing patients by this modality may result in overtreatment of those who are subsequently proved not to have cervical intraepithelial neoplasia. We agree with this as $31(5 \%)$ of our 616 patients subjected to loop diathermy excision had no evidence of preinvasive disease and a further $137(22 \%)$ had koilocytosis only. This subgroup, however, represents a minority of patients and, though such a practice might be regarded as unacceptable if the treatment carried a high morbidity, we believe that the low morbidity and rapid return of the cytological appearances to normal justify the programme. Techniques previously employed such as destruction of the transformation zone may also have had an overtreatment effect, but as the whole transformation zone was not subjected to further analysis this can only be assumed. After exclusion of cancer women regard a negative smear as the primary objective of treatment. Until it is possible to preselect more accurately we must accept a small degree of overtreatment for the overall benefit of women with abnormal cervical smears.

This programme was not comparative and therefore didactic statements of comparison with other forms of treatment cannot be made. It is, however, pertinent to draw attention to the main differences between diathermy excision and laser vaporisation, which has achieved popularity over the past 10 years. Diathermy is not ablative and can therefore be used without prior histological assessment. Though laser may be used in an excisional mode, this is more time consuming and requires greater skill and more expensive hardware. A diathermy generator, like laser, is a multipurpose hospital instrument, yet lasers are at least 10 times more expensive and their annual maintenance cost as much as a diathermy generator. The cost of disposable equipment (wire loops and diathermy contact pads) should be considered, yet even after considerable use over the span of this treatment programme the costs were less than a laser maintenance contract alone. The increase in pathological workload represents an additional cost (although not when loop excision is compared with other excisional techniques), although the better quality of biopsy might be regarded as an increase in the standard of overall care.
The frequency with which we noted both glandular abnormalities and stages $\mathrm{Ia}_{1}$ and $\mathrm{Ia}_{2}$ carcinoma in a population thought suitable for local destruction on colposcopic and cytological grounds was not surprising. We have stated previously that the incidence of adenocarcinoma in situ has probably been underestimated, ${ }^{4}$ and Anderson also believed this in respect of early squamous lesions. ${ }^{5}$ It is unusual for patients to develop invasive cancer of the cervix after local destructive treatment, though cases may occur. It is tempting to suggest that providing whole transformation zones for biopsy may help prevent this by identifying patients at risk.

The success rate of treatment by loop diathermy excision compares favourably with that quoted for other treatment modalities such as laser $^{6}$ and cold coagulation, ${ }^{7}$ and the results of our preliminary programme analysis suggest that loop excision can be accomplished rapidly with minimal morbidity and discomfort. Future fertility will remain a pertinent question, yet certainly the volume of tissue removed by the technique is similar to that ablated by the carbon dioxide laser, and at present there are no indications that the technique has added to problems with conception. Cytological and colposcopic outcome is comparable to that of other modes of outpatient treatment, with $8.9 \%$ potential failures and $4 \cdot 4 \%$ confirmed failures in this series; this outcome may be achieved by treatment at the first visit. The improved histology allowed the identification of conditions such as adénocarcinoma in situ and stages $\mathrm{Ia}_{1}$ and $\mathrm{Ia}_{2}$ cervical carcinoma and thus enabled additional treatment to be planned. Such an effective excisional treatment mode carries clear advantages to the patient in a more rapid return of the cytological appearances to normal and fewer visits to the clinic.

Clinicians concerned in the management of patients with abnormal cervical smears should consider outpatient loop excision as a cost effective alternative to the traditional laser approach.

\section{Cartier R, Sopena B, Cartier I. Use of the diathermy loop in the diagnosis and treatment of lesions of the uterine cervix [Abstract]. Proceedings of
International Federation for Cervical Pathology and Colposcopy. London, 1981. 2 Prendiville W, Sheperd A, Davies WAR. A low voltage diathermy loop for taking cervical biopsies. A qualitative comparison with punch biopsy forceps. Br $\mathcal{F}$ Obstet Gynaecol 1986:93:773-6. \\ 3 Woodman CBJ, Williams D, Yates M, Tomlinson K, Ward K, Luesley DM Indicators of effective cytological sampling of the uterine cervix. Lance 1989;ii:88-90. \\ 4 Luesley DM, Jordan JA, Woodman CBJ, Watson N, Williams DR, Waddell C A retrospective review of adenocarcinoma-in-situ and glandular atypia of the uterine cervix. Br f Obstet Gynaecol 1987;94:699-703. \\ 5 Anderson MC. Are we vaporizing microinvasive lesions? In: Sharp F, Jordan $\mathrm{JA}$, eds. Gynaecological laser surgery (proceedings of the XV RCOG study group). London: Perinatology Press, 1985:127-32. \\ 6 Jordan JA, Woodman CBJ, Myelotte MJ, et al. The treatment of cervical intra epithelial neoplasia by laser vaporization. Br f Obstet Gynaecol 1985;92: $394-8$ \\ 7 Duncan ID. Treatment of $\mathrm{CIN}$ by destruction 'cold' coagulator. In: Jordan JA, Sharp F, Singer A, eds. Pre-clinical neoplasia of the cervix (proceedings of the IX $R C O G$ study group . London: Roval College of Obstetricians and Gynae- cologists, 1981:197-204.}

(Accepted 3 April 1990)
We have seen a prospectus of the "New London Cemetery and Crematorium, Limited," proposing to establish a new cemetery on a plot of fiftytwo acres of land near Mitcham, Surrey. The directors propose also to erect a crematorium thereon, alleging as a reason that the nearest is at present twenty-four miles distant from London. The names of many of the prominent supporters of cremation are cited in support of the system. It appears to be a most undesirable proceeding to devote more land so near to our rapidly increasing metropolis to burial purposes. The suburbs will soon be densely populated, and such a cemetery will soon become practically intramural and a source of danger. The transport of bodies by rail also is quite as easy for fifty miles and upwards as for ten, and much better accomplished than by road conveyances. Waste land at a distance ought to be utilised, and not plots of the most valuable, whether regarded as fertile land or as building land, lying near our gates. 